\title{
Inclusão produtiva: análise exploratória do Programa Todos Somos Porto Alegre
}

\author{
Vanessa Voltaire ${ }^{1}$, Francine da Silva Ladeira ${ }^{1}$, Talyta Medeiros Tatsch ${ }^{1}$, \\ Celmar Corrêa de Oliveira ${ }^{1}$
}

${ }^{1}$ Universidade Estadual do Rio Grande do Sul, Campus Central. Av. Bento Gonçalves, 8855. Bairro Agronomia. Porto Alegre. Rio Grande do Sul. Brasil. CEP: 91540-000.

ISSN 2448-0479

Resumo - O presente trabalho teve como objetivo principal analisar a ocorrência da inclusão produtiva de catadores de resíduos sólidos mediante o programa "Todos Somos Porto Alegre", promovido por parceria entre a Prefeitura Municipal da capital gaúcha e a Organizaçấo Não-Governamental "Mãos Verdes", concorrendo, para tanto, em um esforço de definição do conceito de Inclusão Produtiva conforme vêm sendo adotado pela legislação vigente e referencial teórico. Nossos objetivos específicos foram estudar como está se dando a implementação do programa, bem como realizar a comparação da bibliografia pesquisada, analisando suas etapas, as dificuldades encontradas e o andamento do processo. O referencial teórico apoiou-se nos conceitos de inclusão social e produtiva enquanto forma de cidadania ampliada, Doyal e Gough (1991; 1994); e nos conceitos de desenvolvimento como liberdade, valendo-se de políticas de redistribuição e apoio ao desenvolvimento, Amartya Sen (1999) e Thomas Pikkety (2014). Os resultados iniciais do trabalho, embora as dificuldades de acesso aos dados não permitam a generalizaçáo de conclusóes, indicam que o programa estudado apresenta limitaçôes em promover a inclusão social e produtiva dos catadores de forma efetiva.

Palavras-Chave - Políticas de Inclusão Social. Necessidades Humanas Básicas. Resíduos Sólidos Urbanos. Catadores de Resíduos.

Abstract - The present study aimed at analyzing the productive inclusion of solid waste pickers through the program "Todos Somos Porto Alegre", promoted through a partnership between the Municipality of Porto Alegre and the non-governmental organization Green Hands. The notion of Productive Inclusion as adopted by the current legislation and by some scholars is provided. Our specific objectives were to study how the program implementation is being done as well as to compare data from the studied literature, analyzing the program stages, the encountered difficulties and its progress. The theoretical framework used in this study is based on the concepts of social and productive inclusion as a means of expanding citizenship consciousness as defended by Doyal and Gough (1991; 1994); and the concept of development as freedom, through redistribution policies and development support policies, as proposed by Amartya Sen (1999) and Thomas Pikkety (2014). Although the difficult access to data do not allow us to generalize findings, the initial results of the work indicate that the evaluated program faces difficulties in promoting the social and productive inclusion of waste pickers.

Keywords - Social Inclusion Policies. Basic Human Needs. Urban Solid Waste. Pickers Solid Waste.

Recebido em: 09 de dezembro de 2015

Aprovado em: 28 de março de 2016

\section{INTRODUÇÃO}

As restriçôes de oportunidades econômicas, sociais e políticas e a falta de condiçóes de acesso à saúde de qualidade e à educação limitam a liberdade 
de cada indivíduo em agir de forma eficaz para contribuir com o progresso econômico. Nesse sentido, a inclusão produtiva pressupóe uma articulação das necessidades básicas do ser humano com a promoção do crescimento econômico (SEN, 1999).

O aumento das capacidades humanas é extremamente importante para o desenvolvimento da autonomia, pois estas diminuem as privaçôes e interferem no poder de obter renda. Entretanto, as políticas não podem se restringir ao simples acesso ao mercado de trabalho, devem ser somadas aos direitos econômicos e sociais, buscando o alcance efetivo da inclusão social. A liberdade é um meio para um desenvolvimento com maior alcance, mas possui diversas variáveis com as quais precisamos trabalhar (SEN, 1999).

As instituições com as quais as pessoas identificam-se como atores de transformação são fundamentais ao reconhecimento como cidadáos e, por isso, exercem papel relevante para a sociedade. Por meio dessas interações, é possível ter relações mutuamente benéficas; o que não ocorre quando há uma forma de trabalho tirânica ou a ausência de emprego, situaçôes que restringem a liberdade do indivíduo. Por isso, é importante proporcionar o desenvolvimento de uma forma mais ampla e criar espaços e meios com os quais as pessoas se sintam autônomas e onde possam agir sem restriçôes ao seu bem-estar (SEN, 1999).

A catação de resíduos por homens, mulheres e crianças em situação de vulnerabilidade social revela um dos efeitos da acentuada concentraçáo de renda na qual permanece historicamente nosso país. Os catadores sobrevivem trabalhando de forma extremamente precarizada, expostos a intempéries, em condições insalubres, não dispondo das condiçôes ou mesmo dos conhecimentos necessários para o manejo correto dos diversos tipos de materiais com os quais lidam diariamente.

A atuação destes catadores, ao mesmo tempo, está relacionada a um dos principais problemas urbanos enfrentados pela sociedade contemporânea, que é a destinação final correta dos resíduos produzidos e descartados em nossas cidades. Nesse sentido, adquirem relevância, nas últimas duas décadas, as políticas sociais que buscam incluir os trabalhadores que vivem da coleta de resíduos, de forma a viabilizar sua inclusão social e produtiva. Esta tendência ocorre, especialmente, a partir da regulamentação do Sistema Único de Assistência Social - SUAS - e da organização dessa categoria em torno de objetivos comuns.

O presente trabalho tem como objetivo principal analisar como se dá a inclusão produtiva de catadores de resíduos sólidos através do programa "Todos Somos Porto Alegre", a fim de estudar como transcorre a implementaçáo do programa, bem como realizar a comparação da bibliografia pesquisada, analisando suas etapas, as dificuldades encontradas e o andamento do processo. Desta forma, busca-se responder a seguinte questão: como a estruturação do programa "Todos Somos Porto Alegre” propicia a inclusão produtiva?

\section{REVISÁO BIBLIOGRÁFICA}

Os países europeus têm sido historicamente pioneiros em ações sobre a temática da inclusão social. Na Grã-Bretanha, no ano de 1795, já se discutia rendimento mínimo, garantido com a criação da Speenhamland, lei que reconhecia o direito de todos os homens a um mínimo de subsistência. Desde aquele momento até os dias atuais os países europeus, hoje organizados no bloco político econômico da Uniāo Europeia, têm mantido políticas públicas para a garantia da inclusão social.

Em 2010, foi apresentada a estratégia Europa 2020, com a elaboração da Plataforma Europeia contra a Pobreza e Exclusão Social. Esta Plataforma visa ao desenvolvimento de políticas públicas para erradicação da pobreza e exclusão social no contexto europeu, apontando as principais formas de atuaçáo e atores envolvidos. Uma das maiores preocupaçóes está relacionada aos cidadãos ativos em situação de desemprego. O desemprego afeta a sociedade em diversos aspectos, como a exclusão habitacional; a pobreza de combustível, fator extremamente importante a uma sociedade que vive em países com temperaturas muito baixas; e a exclusão financeira, gerando falta de acesso a serviços bancários básicos e endividamentos (UNIÁO EUROPEIA, 2011).

É necessário dotar as pessoas de competências para inserção no mercado de trabalho, garantindo não só que tenham um emprego, mas que este seja de qualidade e sustentável. Por este motivo é realizado um movimento de capacitaçâo de jovens e cidadãos ativos, para que tenham educação de qualidade e qualificação profissional. Outros pontos de atuaçáo da Plataforma estáo na melhoria da qualidade do ensino nas séries iniciais, de forma que as crianças tenham um desenvolvimento futuro de qualidade no âmbito profissional; $\mathrm{e}$ na busca pelo envelhecimento ativo, com a criação de condiçôes para que os cidadãos mais velhos permaneçam por mais tempo no mercado de trabalho. A Euro- 
pa tem grande preocupação com este nicho da população, que está envelhecendo e que pode prejudicar a sustentabilidade dos sistemas de pensóes.

A partir do levantamento das áreas para o combate à pobreza e à exclusão foi descrita a forma de atuação por meio de políticas setoriais que dão acesso a serviços de transportes, energia e Tecnologia da Informação. Esses serviços integram as necessidades básicas das sociedades desenvolvidas.

Como parte das estratégias Europa 2020, deve ser realizada a revisão do orçamento, evidenciando a necessidade de desenvolvimento dos grupos mais vulneráveis e gerando benefícios para todos. São criados fundos que devem ser gastos inteligentemente por meio de abordagens inovadoras, complementando ferramentas já existentes e garantindo sua eficácia. A União Europeia aplica a chamada experimentação social, na qual projetos de pequena escala para testar inovações políticas são realizados num grupo de controle com características idênticas. Os programas assim realizados são acompanhados e estão sujeitos a normas de avaliaçáo que garantem que seus resultados sejam transferíveis para outros contextos.

No contexto nacional, a discussão sobre a inclusão social e o desenvolvimento de políticas assistenciais no Brasil é uma pauta recente, que se consolida, sobretudo, a partir da promulgação da Constituição Federal de 1988. Até entáo, o entendimento das questôes sociais no Brasil variava entre a promoção de ações isoladas e assistencialistas à criminalizaçâo direta das populaçôes marginalizadas. De fato, conforme apontam Lonardoni et. al. (2006), até o início do século XX não havia uma compreensão da pobreza enquanto expressão de uma questáo social, e quando esta emergia para a sociedade, era tratada como caso de polícia e problematizada por intermédio de seus aparelhos repressivos. Dessa forma, a pobreza era tratada como uma disfunção individual.

No decorrer do século passado, esta relação passa por diversas transformações, sem, contudo, conseguir adentrar o território de discussão dos direitos. Silva (2012, p. 19):

\footnotetext{
O histórico da Assistência Social no Brasil é longo e pautado na caridade, no favoritismo, nas relaçóes clientelistas e na tão reatualizada filantropia. Nesse histórico evidencia-se a priorização do assistencialismo em detrimento do direito, onde as açóes saem do âmbito do Estado sendo referenciadas nas questôes morais e na vida privada [...].
}

O período de exceção civil-militar manteve essa característica, sendo marcado pelo recrudescimento da repressão aos direitos civis e reivindicações sociais. Essa situaçáo se manteve até, pelo menos, meados dos anos 1980, período marcado por intensas mobilizaçôes sociais e pelas discussóes que levariam à promulgação de nossa atual Constituição, marco diferencial nas políticas de assistência social no Brasil - ou, pelo menos, em sua regulamentação.

Com a Constituição de 1988 passa a existir a perspectiva de construção de um padrão público universal de proteção social, com previsão regulamentada no campo dos direitos - consequência do processo de lutas da sociedade civil em busca do fortalecimento dos direitos sociais (SILVA, 2012). Ainda assim, percebe-se que a regulamentação destes direitos passou por uma conjuntura de disputas complexa e hostil - demonstrando que mesmo sua firmação em letra escrita não constitui força suficiente para a superação de uma cultura enraizada de assistencialismo e fragmentação das políticas públicas.

A Lei Orgânica da Assistência Social - LOAS (Lei 8.742/93) foi o diploma legal que regulamentou e materializou os artigos da Constituição em relação à Assistência Social, buscando superar o critério de clientelismo para reafirmar o preceito constitucional de assistência social como direito. Ao mesmo tempo, foi responsável pela organização do Sistema Único de Assistência Social - SUAS - sistema público que organiza, de forma descentralizada, os serviços socioassistenciais no Brasil. Assim, percebe-se que a regulamentação e a coordenação das atividades da assistência social no Brasil obtiveram esse impulso há apenas duas décadas, configurando-se como políticas de expressão bastante recente.

Com isto, identifica-se o reconhecimento público da responsabilidade social do Estado, a constitucionalização do gasto social e a adoção explícita do enfoque dos direitos no desenho e implementação das políticas sociais (TRUJILLO, 2014).

A partir dos anos 2000, a articulação de programas voltados ao atendimento de populaçóes em situação de extrema miséria passa a ser pautada pelos eixos de acesso a serviços públicos, garantia de renda e da inclusão produtiva. Este último eixo tem sido evocado presentemente em políticas sociais mais recentes e das mais diversas esferas governamentais - por exemplo, no programa "Todos Somos Porto Alegre". Trata-se, de conceito que objetiva propiciar o acesso da população em extrema pobreza a oportunidades 
de ocupação e renda, prevendo assim a possibilidade de emancipaçáo econômica dessa população mediante sua inserção no mercado de trabalho (SOUZA, 2013, p. 291).

\subsection{Inclusão produtiva: processo ou autonomia?}

Conceituar inclusão produtiva ainda é um processo que está posto para a comunidade acadêmica, especialmente no que se refere a sua alternância entre a compreensão de processo e autonomia. Souza (2013) aponta para a ausência de uma conceituação clara a respeito do termo inclusão produtiva, especialmente pela sua recente adoção no âmbito das políticas públicas e por sua discussão ainda incipiente dentro da academia. De modo geral, a construção inicial do conceito se deu no âmbito das políticas de combate à fome promovidas pelo Ministério do Desenvolvimento Social (MDS), mais especificamente na Secretaria de Articulação para a Inclusão Produtiva (SAIP), que se baseou no Decreto 6.393 de março de 2008, apontando para a inclusão produtiva como um "processo que conduz à formação de cidadãos, integrados ao mundo através do trabalho" (SOUZA, 2013, p. 291).

Contudo, há que se admitir que tal formulação apresente evidente limitação, tornando-se necessário aprofundar a reflexão não apenas sobre a concepção do termo, mas principalmente das intençóes e das consequências promovidas por sua adoçáo no âmbito das políticas públicas socioassistenciais.

Rodrigues e Almeida (2013, p. 200), ao tentar elaborar um conceito que dê conta desta temática, apontam que:

\section{"[...] sob enfoque produtivo, a inclusão deve con- duzir à formação de cidadãos integrados ao mundo pelo trabalho tendo como perspectiva a conquista de autonomia para uma vida digna e autossus- tentada por parte das pessoas que estão excluidas ou fragilmente vinculadas à produção de renda e riqueza [...]."}

À semelhança da sentença anterior, percebe-se o enfoque na ideia de inclusão pelo trabalho, agregado à ideia de emancipação financeira do beneficiário.

Para identificar um conceito mais abrangente dos objetivos por trás da inclusão produtiva enquanto ação e política de governo, analisamos a definição apresentada nas diretrizes gerais da Fundação de Assistência Social e Cidadania de Porto Alegre (2010, p. 35):

\begin{abstract}
"A promoção da inclusão produtiva é concebida no seu sentido ampliado, significando o fortalecimento dos vínculos sociais, familiares e comunitários, por meio do desenvolvimento de capacidades e condiçóes para agir com autonomia, potencializando o protagonismo em açóes coletivas no campo da produção material e social. Por fim, as açôes de inclusão têm como escopo o fortalecimento da organização social da comunidade beneficiária e a melhoria da qualidade de vida [...]."
\end{abstract}

Através desta abordagem, percebe-se uma visão mais abrangente, que contempla a ideia de que políticas sociais de inclusão produtiva devem ter por objetivo a promoção da cidadania em seu aspecto ampliado, isto é, para além de uma perspectiva meramente financeira. Desta forma, ao pensar a inclusão produtiva, compreendemos que este fenômeno deve prezar pela concepção de ampliação dos direitos, mais que como simples mecanismo de emancipação financeira; e, ainda, deve ser encarado enquanto açáo que vise à promoçáo da cidadania em seu sentido coletivo, ante um conceito voltado para o atendimento centrado no indivíduo.

A ideia de cidadania ampliada que o conceito de inclusão produtiva traz consigo como direito e justiça social converge com aspectos levantados por Len Doyal e Ian Gough em sua teoria das necessidades humanas. Nela, os autores apontam para a existência de necessidades humanas básicas, objetivas e universais, que se encontram vinculadas à garantia de sobrevivência (saúde física) e autonomia do indivíduo, sendo estas condiçôes prévias para a consecução de suas potencialidades enquanto ser humano (DOYAL, GOUGH, 1994). A natureza mais profunda dessas necessidades encontra-se em sua universalidade, no sentido de que indicam a existência de necessidades elementares, comuns a todos os seres humanos, em todos os tempos ou lugares. São verdadeiros imperativos humanos que, sem atendimento, homens e mulheres não poderão existir digna ou plenamente.

Porém, para que essas necessidades básicas sejam atendidas, os autores citam outras onze necessidades, às quais denominam necessidades intermediárias, que se apresentam como imprescindíveis para a efetivação das primeiras. Entre elas, estão questôes como segurança física e econômica, proteção à infância, educação e alimentaçáo adequadas, ambientes de moradia e trabalho saudáveis e seguros, entre outras. Em comum, o fato de se constituírem enquanto valores uni- 
versais que se agregam para a satisfação das condições básicas de saúde física e autonomia dos indivíduos.

Por sua vez, esse entendimento se aproxima do enfoque das capacidades desenvolvido por Amartya Sen $(1993 ; 2000)$. A ideia subjacente a essa teoria remete para a concepção de que indivíduos que possuem maior acesso a oportunidades - como educação básica, saúde, alimentaçấo - terão mais recursos a sua disposição, ou seja, mais escolhas disponíveis, tornando-se, portanto, mais capazes de escapar à pobreza. $\mathrm{O}$ autor destaca a centralidade destas oportunidades, ou liberdades positivas, como determinantes à realizaçâo das possibilidades do indivíduo.

Segundo Sen, (1993, p. 223):

\section{"O conjunto de capacidades representa a liberdade pessoal de realizar várias combinaçôes de efetiva- çôes. Se a liberdade é intrinsecamente importante, as combinaçōes disponiveis para a escolha são todas relevantes para se avaliar o que é vantajoso para uma pessoa, mesmo que ele ou ela escolha apenas uma alternativa. Nessa perspectiva, a escolha é, em si mesma, uma característica valiosa da vida de uma pessoa [...]."}

Assim, o autor aponta que o desenvolvimento de um país estará intrinsecamente ligado às oportunidades oferecidas à sua populaçấo para o exercício da plena cidadania. A esse conceito o autor denomina desenvolvimento como liberdade, que também veio a ser o título de uma de suas principais obras (SEN, 2000).

O que Sen procura demonstrar é que o desenvolvimento deve ser visto como um processo de expansáo das liberdades positivas, mais que o crescimento do Produto Interno Bruto (PIB) ou das rendas individuais. Contudo, enfatiza que as liberdades dependem também de outros determinantes, como fatores sociais e econômicos, por exemplo: serviços de educação e saúde e direitos civis. Assim, a ausência de liberdades substantivas pode se mostrar intrinsecamente ligada à condiçấo de pobreza econômica, vez que essa subtrai às pessoas as oportunidades necessárias à realizaçáo de suas necessidades básicas. E o mesmo se aplica à ausência de serviços públicos e políticas socioassistenciais (SEN, 1999).

Reforçando um entendimento nesse sentido, Thomas Piketty (2014) propóe a necessidade do desenvolvimento de políticas públicas de redistribuição que funcionem como vetores de apoio ao desenvolvi- mento coletivo. Segundo o autor (2014, p. 106, a), há situaçôes onde a desigualdade exige:

"uma ação coletiva não só por ir contra o nosso senso

de justiça social, como por representar um imenso desperdicio de recursos humanos que poderiam ser mais bem utilizados em benefício de todos".

Como forma de atuar frente a essas situaçóes, o autor defende a existência do que chama de mecanismos de redistribuição eficiente. Esses instrumentos permitem a redistribuiçáo efetiva de renda, como políticas de ações afirmativas, de salário mínimo, ou, mais genericamente, intervençôes diretas no mercado de trabalho. O autor aponta, ainda, como medidas eficazes no processo de combate às desigualdades socioeconômicas as políticas de educação e formação, em suas diversas formas, que permitiriam "modificar estruturalmente a desigualdade das rendas do trabalho", contribuindo para solucionar a complexa questão da desigualdade social.

Em suma, a redistribuição moderna consiste em um financiamento dos serviços públicos e das rendas de substituição de forma mais ou menos igualitária para todos, especialmente nos domínios da educação, saúde e aposentadorias (PIKETTY, 2014).

Contudo, formular políticas públicas de inclusão social não tem se mostrado uma tarefa fácil, principalmente, quando existe a necessidade de convergir crescimento econômico e altos investimentos para a garantia da seguridade social. A Plataforma Europeia contra a Pobreza e a Exclusão Social propõe-se a enfrentar esta questão vinculando a retomada do crescimento econômico da União Europeia com a geração de empregos. O próprio texto de apresentação (União Europeia, 2011, p.10) define que:

\begin{abstract}
"A luta contra a pobreza e a exclusão têm de se assentar no crescimento e no emprego, bem como em sistemas de proteção social modernos e eficientes. Acresce que uma intervenção inovadora da proteção social deve ser articulada com um amplo conjunto de politicas, designadamente nos dominios da educação, cuidados sociais, habitação, saúde, família e conciliaçâa entre vida profissional e privada. Até agora, em todas estas áreas, a intervenção dos sistemas de previdência tende a fazer-se através de programas assistenciais fragmentados [...]."
\end{abstract}

Trata-se, portanto, de um conjunto de diretrizes comuns aos Estados-Membros da Uniáo Europeia com 
o objetivo de retirar da pobreza (ou risco de pobreza) e exclusão social vinte milhóes de pessoas residentes nesses Estados até o ano de 2020. Para isso vinculam a geração de empregos com a promoçáo da inclusão social de forma articulada, se materializando em um conjunto de políticas de proteção social integrada.

\subsection{Plano Nacional de Resíduos Sólidos}

No ano de 2011, determinado pela Lei $12.305 / 10$, foi elaborada a primeira versão preliminar do Plano Nacional de Resíduos Sólidos. Esse plano estipula metas, diretrizes e estratégias para a redução, o reaproveitamento e a disposiçáo correta de resíduos para os próximos vinte anos, e prevê revisōes a cada quatro anos. Estấo envolvidos neste processo desde entidades públicas vinculadas ao tema - como o Ministério do Meio Ambiente (MMA) - Uniāo, Estados, Municípios, empresas, até cidadáos; portanto, ele é de responsabilidade de pessoas físicas e jurídicas de direito público ou privado, direta ou indiretamente.

A estrutura do Plano Nacional de Resíduos Sólidos é dividida em quatro capítulos da seguinte forma: no primeiro capítulo, um diagnóstico por tipos de resíduos, inclusão de catadores, educação ambiental e instrumentos econômicos; no segundo, a construção de três possíveis cenários para os próximos vinte anos. Estes cenários estão divididos em possível, imaginável e desejável; no capítulo três, são apresentadas diretrizes e estratégias também por tipos de resíduos, harmonizando-se com diversas leis já existentes para alguns seguimentos; e, por fim, no quarto capítulo, são estipuladas metas para cada ente envolvido.

Durante o diagnóstico, fica clara a dificuldade em coletar dados sobre o tema. Órgáos responsáveis e empresas possuíam pouco ou nenhum controle relacionado à coleta e destinação dos resíduos. Isto dificulta a criação de metas realmente compatíveis com o cenário atual. No âmbito dos catadores, houve um levantamento de dados secundários e fontes de informação como o Instituto Brasileiro de Geografia e Estatística - IBGE, entre outros órgãos da administração pública, institutos de pesquisa, entidades de classe, revisão bibliográfica, consulta e entrevistas com atores envolvidos, especialistas do governo e sociedade civil. Com base em diferentes fontes, foi estipulada durante a construção do Plano uma estimativa de que haveria entre 400 e 600 mil catadores de materiais recicláveis no Brasil; ao menos 1.100 organizações coletivas de catadores em funcionamento em todo o país; $10 \%$ da população de catadores participava de alguma organização coletiva; a renda média dos catadores não atingia o salário mínimo, alcançando entre R \$ 420,00 e R \$ 520,00 e; a faixa de instruçáo mais observada entre os catadores era da $5^{\mathrm{a}}$ a $8^{\mathrm{a}}$ séries (MMA, 2011).

A coleta seletiva municipalizada acontece há mais de vinte anos e, no período de elaboração do Plano, abrangia apenas $18 \%$ dos municípios brasileiros. Os pontos de melhorias em relação à coleta seletiva são a educação e consciência ambiental. Sendo assim, são apresentadas quatro formas de atuação na sociedade. Esta divisão possibilita um melhor desempenho dos entes envolvidos, criando critérios de acordo com o público alvo. Em relação aos cenários tratados no capítulo dois do Plano - não cabe neste artigo maior aprofundamento sobre a descrição dos mesmos - foram construídos com o intuito de melhorar a tomada de decisóes estratégicas por parte dos gestores e funcionam como norteadores para o alcance de um futuro desejado e possível, também prevendo as consequências em longo prazo. Esta cenarizaçâo foi elaborada no âmbito do Plano Nacional de Saneamento Básico - PNSB. Ainda, conforme previsto no artigo 15 da Lei 12.305/2010 - Política Nacional de Resíduos Sólidos, o Plano Nacional de Resíduos Sólidos (PNRS apresenta as diretrizes e suas respectivas estratégias. As discussões em torno deste assunto aconteceram simultaneamente ao detalhamento do Plano Plurianual (PPA 2012-2015), podendo o Governo Federal por intermédio dos Ministérios relacionados aos temas buscarem um alinhamento dos Programas, Açóes e Projetos de forma a contemplar as Diretrizes do Plano.

A partir das diretrizes, estratégias (PNRS, p. 7173) e cenários desenvolvidos foram projetadas as metas quanto à situação dos resíduos sólidos no Brasil nos próximos vinte anos, que devem ser revisadas de quatro em quatro anos concomitantemente à atualização do PNRS e também ao Plano Plurianual. Considerando o Cenário 1 , onde foi descrito um plano de metas favorável para o país, se faz necessário "uma disponibilidade de recursos na casa de R \$ 9,2 bilhôes, com aporte dos três níveis de governo e da iniciativa privada". Levando-se em conta a dificuldade na busca de dados consolidados sobre o tema, uma das importantes metas é de que todas as Unidades Federativas "concluam os estudos de regionalização em 2012, de modo a viabilizar a implantação dos consórcios ou associaçôes de municípios até 2013”. Esses consórcios nos municípios são estimulados pelo governo para que 
se busque a redução de custos associada à qualificação dos serviços, já que os resíduos serão tratados por empresas especializadas no tema. Isto traria ganho de escala e proporcionaria o alcance de outras metas como: encerramento dos lixões (com sua conclusão prevista em lei até 2014), implantação de aterros sanitários e coleta seletiva com a inclusão dos catadores.

Com um maior repasse de recursos sendo realizado pela União foram estabelecidos alguns passos para os Estados e Municípios contemplados, sendo estes: seleção dos empreendimentos; habilitação dos proponentes e aprovação dos projetos pelo órgão repassador; execução das obras (repasse de recursos); e prestaçáo de contas. Cabe também à União garantir a sustentabilidade dos projetos por meio de bancos federais de fomento, fornecendo linhas de financiamentos à iniciativa privada, já que esta poderá participar na implantação de unidades de tratamento e disposição final de resíduos por meio de Parceria Público Privada (PPP) e concessóes. Quanto aos municípios, deve-se investir no desenvolvimento institucional por meio de suporte político e gerencial para sustentabilidade da prestação dos serviços em cumprimento das premissas previstas na Lei 12.310/2010 e Decreto regulamentador 7.404/2010. O não cumprimento das medidas estruturantes implica não alcançar as metas estabelecidas neste cenário.

\section{MATERIAIS E MÉTODOS}

A hipótese de pesquisa parte do pressuposto de que programas de geração de trabalho e renda contribuem para a inclusão produtiva e inserção socioeconômica dos agentes beneficiados. Nesse sentido, Amartya Sen (1999) defende a ideia de desenvolvimento como liberdade, ou seja, a ideia de que indivíduos com maiores liberdades positivas, maiores oportunidades para o desenvolvimento, terão melhores chances de escapar de condições socioeconômicas desfavoráveis.

A pesquisa caracteriza-se como qualitativa, bibliográfica e documental, baseada em um estudo de caso. Conforme aponta Zanella (2009), a pesquisa qualitativa é, por natureza, descritiva, pois se preocupa em descrever os fenômenos por meio dos significados que o ambiente manifesta, prestando-se a retratar as características de um determinado fato. Já os estudos de caso caracterizam-se como uma forma de pesquisa que aborda com profundidade um, ou poucos, objetos de estudo, procurando conhecer a realidade de políticas ou organizaçôes em maior profundidade. Assim, este estudo buscou compreender como se dá a dinâmica de inclusão produtiva de catadores de materiais recicláveis no programa "Todos Somos Porto Alegre”, através de um estudo de caso exploratório.

Neste trabalho foram percorridas as seguintes etapas metodológicas visando legitimar as fontes (triangulação entre políticas de inclusão social, inclusão produtiva e programa TSPA), e, por consequência, alcançar os objetivos e responder o problema da pesquisa:

1) Apresentação da evolução das políticas de inclusão social na Europa e no Brasil;

2) Análise da inclusão produtiva, na perspectiva de autores que propugnam as necessidades humanas básicas, análise do desenvolvimento como processo de expansão das liberdades positivas mais que o crescimento do PIB ou das rendas individuais; e análise sobre a utilização de mecanismos de redistribuição eficiente de renda;

3) Exame de pertinência do programa TSPA com a inclusão produtiva proposta pelos autores que defendem a existência de necessidade humanas básicas.

\section{RESULTADOS E DISCUSSÃO}

O "Programa de Inclusão Produtiva na Reciclagem - Todos Somos Porto Alegre" - é uma iniciativa conjunta da Prefeitura de Porto Alegre, contando com apoio e participação de diversas entidades públicas, privadas e do terceiro setor. O financiamento é realizado pelo Banco Nacional de Desenvolvimento Econômico e Social - BNDES, com a utilização de crédito a fundo perdido. O programa visa à inserção produtiva dos trabalhadores informais envolvidos no processo de recolhimento de resíduos sólidos pelas ruas da cidade, que estâo majoritariamente em situação de exclusão e vulnerabilidade social ("Programa de Inclusão na Reciclagem - TSPA”, 2015).

Além disso, uma melhor gestão e qualificação do processo de reciclagem são extremamente necessárias na conjuntura atual. Isso porque, apesar de a Coleta Seletiva ter sido implantada na cidade de Porto Alegre há vinte e cinco anos, a população porto alegrense (e a brasileira em geral) ainda não realiza a segregação na origem de forma a agilizar o processo de reciclagem. Mesmo a cidade de Porto Alegre sendo pioneira 
na implantação da Coleta Seletiva, segundo dados do PMGIRS, no ano de 2011 a cidade produzia 1.804 toneladas dia de resíduos sólidos, e apenas $4 \%$ dos resíduos eram reciclados, destacando que destes $4 \%, 1 / 4$ refere-se à reciclagem de resíduos orgânicos oriundos de compostagem ou reaproveitamento da suinocultura. Diante deste quadro, verificamos que o que tem sido destinado aos aterros sanitários não é apenas o rejeito, tornando o custo da destinação final dos resíduos sólidos uma conta cada vez mais cara para a sociedade e para o meio ambiente.

O material descartado nos aterros sanitários constitui-se de milhares de toneladas de resíduos misturados não segregados na origem (perdendo desta forma em boa parte o valor comercial para indústria de reciclagem), e não triados nas ruas ou nas Unidades de Triagem e Compostagem de Porto Alegre.

No mesmo compasso do crescimento das políticas públicas de tratamento de resíduos sólidos, cresce a necessidade da implantação de políticas sociais de geração de trabalho e renda para a população que vive da coleta de resíduos recicláveis nos grandes centros urbanos do país.

O "Programa Todos Somos Porto Alegre" trabalha com o conceito de inclusão produtiva, promovendo a qualificação profissional de catadores e unidades de triagem de resíduos pós-consumo.

O programa subdivide-se em três projetos (TODOS SOMOS PORTO ALEGRE, 2015):

Projeto 1 - Inclusão Profissional de Condutores de Veículos de Tração Animal - VTAs e Veículos de Tração Humana - VTHs

Projeto 2 - Reestruturação do Sistema de Unidades Populares de Triagem

Projeto 3 - Educação Ambiental para a Sociedade.

O primeiro projeto visa promover o ingresso de trabalhadores da coleta e separação de resíduos sólidos no mercado formal de trabalho, em contrapartida à restrição gradativa de circulação de veículos de tração humana e veículos de tração animal na Capital, conforme estabelecido pela Lei Municipal 10.531 de 2008. Esta lei previu, além da restrição da circulação destes veículos, a transposiçáo dos condutores para outros mercados de trabalho, por meio da implementação de políticas de inclusão, além de indenização pecuniária pelos veículos recolhidos ("Programa de Inclusão na Reciclagem - TSPA”, 2015).
O segundo projeto trabalha com reestruturação das unidades de triagem, visando transformar a realidade destas unidades e oferecendo condições necessárias para que os catadores tenham melhor renda, bem-estar e compreensáo do potencial de seu negócio ("Programa de Inclusão na Reciclagem TSPA", 2015).

Por fim, o terceiro projeto prevê ações em escolas, universidades e órgãos públicos municipais para repercutir suas estratégias de inclusão e proteção, mobilizando toda a cidade a contribuir e participar da separação, triagem e recuperação de materiais descartados ("Programa de Inclusão na Reciclagem - TSPA", 2015).

No Projeto 1, que trata da inclusão produtiva de catadores que fazem uso de veículos de traçáo humana ou animal, este adota como uma de suas principais estratégias a ação das equipes de busca ativa. As equipes de busca ativa são compostas por técnicos e educadores sociais, que tem como objetivo promover a inserçâo dos catadores nas atividades e benefícios do programa. O trabalho inicia com a abordagem e cadastramento dos interessados, estabelecendo vínculos e acompanhando as pessoas em seu processo de desenvolvimento e qualificação para o ingresso em uma nova atividade produtiva. Para tanto, é oferecido um conjunto de serviços aos trabalhadores e suas famílias para que possam ingressar em cursos de formação profissional com bolsa de estudo, acessar vagas de emprego, receber indenização pelos veículos que utilizam e ser encaminhados, quando for o caso, para outros serviços de atendimento assistencial ("Programa de Inclusão na Reciclagem - TSPA”, 2015).

No acompanhamento dos resultados das atividades programadas, é utilizado o Sistema Gerencial de Busca Ativa (SIGBA) que tem o objetivo de gerar informaçôes sobre o processo de cada beneficiário participante. Esta ferramenta é considerada fundamental pelos gestores do programa, enquanto instrumento para o estabelecimento de metas, identificação de problemas e planejamento de novas açôes, configurando-se como uma das principais fontes de análise deste trabalho ("Programa de Inclusão na Reciclagem - TSPA”, 2015).

Um aspecto fundamental na formação de catadores é sua capacitaçáo para atuar em toda a cadeia produtiva dos resíduos sólidos, não apenas na triagem dos materiais recicláveis, mas também no seu beneficiamento e reciclagem, etapas de maior valor agregado. Essa, de fato, é a maneira mais efetiva de 
lutar contra a exploração econômica a que estão submetidos. Nesse sentido, é fundamental a construção de políticas de investimentos social de apoio às cooperativas, indo além do processo de remanejamento setorial desses trabalhadores. Por isso, verifica-se que o conjunto de açóes previstas no programa em análise, para além da retirada destes trabalhadores das ruas, torna-se crucial, constituindo-se nosso maior interesse avaliar os resultados que vêm sendo obtidos pelo Projeto1, mais diretamente ligado à questáo da inclusão produtiva destes catadores em atividades socioeconômicas. Desta forma, busca-se, nas próximas seções, identificar quais os resultados que estão sendo obtidos por esta ação, a partir da verificação dos dados disponibilizados no sistema SIGBA, além das informaçóes provenientes das entrevistas realizadas com gestores e participantes do programa e dos materiais institucionais analisados durante a pesquisa.

\subsection{Análise do programa}

A análise dos dados apresentados é decorrente de um esforço para compreender o trabalho realizado pelo programa "Todos Somos Porto Alegre". Estes dados de execução do programa têm origem em informaçóes dos gestores da Organizaçấo Não-Governamental "Mãos Verdes" e na página desta Organização.

A fonte não disponibiliza a metodologia utilizada para mensuraçáo dos dados, nem apresenta com clareza a que período se referem. Além disso, estes dados não seguem uma lógica comparativa ou progressiva. Outra dificuldade encontrada foi a inconsistência dos dados entre os relatórios apresentados. Por exemplo, os dados do primeiro relatório apontam 2.306 representantes familiares cadastrados; porém, nos materiais publicados posteriormente, este número diminui para 2.059. Segundo os dados deste relatório, até abril de 2015, na Busca Ativa / Inclusão Direta, 995 catadores foram beneficiados pelos projetos de formação e capacitação ofertados pelo programa.

De acordo com este relatório, 449 beneficiários foram capacitados, 322 beneficiários foram habilitados para acessar outra forma alternativa de renda, (este dado não é claro no sentido de que não demonstra que outra forma alternativa de renda se trata). Outras 187 pessoas receberam encaminhamentos sociais, o que sugere que este público recebeu encaminhamento para ingressar com benefícios sociais do governo. Esta medida não se trata de ação de inclusão produtiva, que é o escopo do programa.
O material ainda informa um montante na ordem de cerca R \$ 664.042,48 investidos em bolsas de formação, ou seja, bolsas que são pagas aos trabalhadores que abandonam a atividade de coleta de resíduos durante seu período de capacitação. Além disso, as informações do relatório dão conta de um investimento na ordem de $\mathrm{R} \$ 229.500,00$ que se reportam ao ressarcimento dos veículos de tração e animais recolhidos das ruas, conforme previsto em legislação, num valor médio de $\mathrm{R} \$ 800$ por indenização.

Embora estas cifras deixem claro que a formação dos trabalhadores desempenhe papel central no conceito de inclusão produtiva, conforme pensado no âmbito desta política, é forçoso lembrar que este não se trata do resultado final almejado: os dados disponibilizados na página da Organização Não-Governamental não dispóem, em nenhum momento, do número de trabalhadores efetivamente inseridos no mercado de trabalho. Em outras palavras, não há ainda visibilidade da inclusão produtiva promovida pelo programa. Ainda, os dados constantes no SIGBA, relevantes para o objetivo deste estudo, não foram disponibilizados pelos gestores do programa, nem estão disponíveis na página da Organizaçấo Não-Governamental "Mãos Verdes".

A realização de uma análise adequada desta política pública carece de dados que possibilitassem respostas a perguntas básicas como: qual o número total de pessoas que vivem da atividade de cataçáo informal em Porto Alegre? Qual o número de pessoas beneficiadas pelo programa? Qual o número de pessoas que concluíram a capacitação do programa? E qual o número de pessoas inseridas produtivamente (capacitação + programa de inclusão produtiva)?

Informar o número de pessoas que vivem da atividade da catação informal é uma dificuldade posta para os gestores que trabalham com esta temática em todo Brasil. Esta mesma dificuldade foi apontada no momento da construção do diagnóstico preliminar do Plano Nacional de Resíduos Sólidos, em 2011, com uma estimativa de 400 a 600 mil catadores de materiais recicláveis no Brasil, obtida através de dados secundários.

Um dos materiais de apresentação do programa "Todos Somos Porto Alegre" coloca como meta de atendimento 1.200 catadores e um total de 5.400 pessoas atendidas pelo programa (TODOS SOMOS PORTO ALEGRE, 2015). Acreditamos que estes números não reflitam uma disponibilidade que atenda à necessidade real de inclusão produtiva dos catadores de Porto Alegre. 
Se o PNRS (2011) apresenta uma média aproximada de 500 mil catadores no Brasil e (segundo dados do IBGE em 2011) a população brasileira e porto-alegrense eram em torno de 194 milhóes e de 1,410 milhōes, respectivamente, a proporção de catadores em Porto Alegre seria de aproximadamente 3.634 mil pessoas. Usando esta projeção, e excluídas outras variáveis, poderíamos sinalizar que o atendimento de 1.200 catadores pelo programa daria conta de apenas $1 / 3$ da demanda de inclusão para catadores no município de Porto Alegre.

Por fim, a resposta para estes questionamentos não pode ser obtida nesta fase em que o programa se encontra, em vista de que os dados disponibilizados até o presente momento, são insuficientes.

\section{CONCLUSÃO}

Este artigo buscou contribuir para o debate acerca da realização da inclusão produtiva de catadores de resíduos sólidos, tendo por referência a promoção de políticas socioassistenciais de inclusão social voltadas para esse público. Em um período que recebe relevância a ampliação da assistência social enquanto política de direitos, em contraponto a um ponto de vista histórico marcado por açōes assistencialistas, pontuais e pautadas pelo discurso do favorecimento e da filantropia de Estado, se faz necessário refletir sobre os resultados obtidos por estas ações. Nesse contexto, buscamos analisar o programa "Todos Somos Porto Alegre", projeto desenvolvido na capital gaúcha, com parceria entre órgãos de governo, empresas e terceiro setor, que em seu discurso se volta essencialmente para a promoção da inclusão de catadores e seus familiares no processo produtivo, valendo-se de açôes voltadas à capacitação, educação e valorização dos espaços de trabalho destas famílias em suas atividades laborais.

Os resultados encontrados demonstram que o programa se encontra em sua fase de implementação, sendo em geral inconsistentes. Contudo, vale notar que, em comparação ao elevado volume de recursos já utilizados, o programa apresenta dificuldades na obtençấo de resultados concretos, visto que não traduzem uma inclusão efetiva desses trabalhadores em postos de trabalho formal, ou outros indicadores que apontem sua inclusão social e produtiva, no sentido de ampliação de seus direitos.

A dificuldade de acesso a dados gerenciais atualizados do programa, que dessem conta de aspectos mais amplos a respeito dos investimentos realizados em suas açóes específicas criaram dificuldades para uma análise mais aprofundada, impedindo conclusóes mais gerais acerca de seus resultados. De modo geral, foi possível perceber um distanciamento entre os resultados encontrados e o referencial adotado. Esse distanciamento poderia ter, dentre outras causas, fatores como falhas de planejamento, investimento inadequado ou acompanhamento insuficiente.

A análise dos resultados iniciais do programa, portanto - enfatize-se que apesar da dificuldade de acesso aos dados e o caráter inicial desta reflexão -, sugere dificuldades do programa "Todos Somos Porto Alegre" em promover a inclusão produtiva de trabalhadores vinculados a atividades de coleta de resíduos sólidos e suas famílias.

Os resultados iniciais apresentados pelo programa, igualmente, não invalidam a hipótese apresentada - programas de geração de trabalho e renda contribuem para a inclusão produtiva e inserção socioeconômica dos agentes beneficiados - posto que, este pressuposto foi amplamente fundamentado, no referencial teórico, deste artigo.

Recomenda-se novos estudos acerca das políticas sociais, com especial interesse para o acompanhamento de programas de inclusão produtiva, a fim de verificar se contribuem, efetivamente, para a promoção de uma sociedade mais justa e se propiciam mais oportunidades para aqueles que mais necessitam.

\section{REFERÊNCIAS}

BEHRING, E.R. \& Boschetti, I. Política social: fundamentos e história. São Paulo: Cortez, 2007.

BORTOLI, M.A. Processos de organizaçáo de catadores de materiais recicláveis: lutas e conformaçóes. Revista Katálysis, Florianópolis, v. 16, n. 2, p. 421-430. 2013.

BUSCA ATIVA - Programa de Inclusão na Reciclagem - Todos Somos Porto Alegre. Disponível em: <http:// www.maosverdes.com.br/\#!busca-ativa/c9id>. Acesso em 08 jun. 2015.

DOYAL, L.; GOUGH, I. A theory of human need. London: Palgrave Macmillan, 1991.

DOYAL, L.; GOUGH, I. O direito à satisfaçáo das necessidades. Lua Nova, Sáo Paulo ,n. 33, p. 97-121, Ago. 1994. Disponível em:<http:// www.scielo.br/scielo.php?script $=$ sci_arttext \&pi$\mathrm{d}=$ S0102-64451994000200008\&lng $=$ en $\& \mathrm{nrm}=$ iso $>$. Acesso em 21 jun. 2015. 
FUNDAÇÃO DE ASSISTÊNCIA SOCIAL E CIDADANIA - Coordenação de Rede de Proteção Social Básica. Implantação Do Sistema Único De Assistência Social - Projeto Técnico do Centro De Referência De Assistência Social - CRAS -- Prefeitura Municipal de Porto Alegre, 2010.

GRIMBERG, E. Coleta seletiva com inclusáo social: Fórum Lixo e Cidadania na Cidade de São Paulo. Experiência e desafios. São Paulo: Instituto Pólis, 2007. 148p.

LONARDONI, Eliana; GIMENES, Junia; SANTOS, Maria Lucia. O processo de afirmação da assistência social como política social. Serviço Social em Revista. Londrina, v 8, n. 2, jan-jun 2008. Disponível em: <http:// www.uel.br/revistas/ssrevista/c-v8n2_sonia.htm>. Acesso em 18 mai. 2015.

MINISTÉRIO DO MEIO AMBIENTE. Plano Nacional de Resíduos Sólidos. Versão Preliminar para Consulta Pública, Brasília, 2011. Disponível em: http://www. mma.gov.br/estruturas/253/_publicacao/253_publicacao02022012041757.pdf. Acesso em 16 jun. 2015.

PIKETTY, T. A Economia da Desigualdade. Tradução: André Telles. Rio de Janeiro: Intrínseca, 2014a.

PIKETTY, T. O capital no século XXI. Tradução: Monica Baumgarten de Bolle. Rio de Janeiro: Intrínseca, 2014b.

PREFEITURA MUNICIPAL DE PORTO ALEGRE. Plano Municipal de Gestáo Integrada de Resíduos Sólidos. Porto Alegre, v. 1, 2013. Disponível em: <http:// lproweb.procempa.com.br/pmpa/prefpoa/dmlu/usu_doc/ pmgirs_porto_alegre_volume_1.pdf >. Acesso em 25 mai. 2015.

RODRIGUES, R.; e ALMEIDA, P. A Contribuiçáo das Associaçóes na Inclusáo Produtiva e Social dos Catadores de Materiais Recicláveis do Município de Fortaleza. Revista do Mestrado Profissional em Planejamento em Políticas Públicas. Fortaleza, v. 1, n. 7, 2013. p. 157-202.

SEN, A. Desenvolvimento como Liberdade. São Paulo: Companhia das Letras, 1999.

SEN, A. O desenvolvimento como expansão de capacidades. Lua Nova, São Paulo, n. 28-29, p. 313-334, Abr. 1993. Disponível em: <http:// www.scielo.br/scielo.php?script=sci_arttext $\&$ pi$\mathrm{d}=\mathrm{S} 0102-64451993000100016 \& \operatorname{lng}=$ en $\& \mathrm{nrm}=\mathrm{iso}>$. Acesso em 21 jun. 2015.

SILVA, F. Assistência social e cultura política: o processo de uma política em construção. 2012. 129 p. Dissertação (Mestrado), Universidade Federal de Juiz de Fora, MG. 2012. Disponível em: <http://www.uff.br/ppgservicosocial/files/2012/05/fernanda.pdf>. Acesso em 18 jun. 2015.

SOUZA, F. Assistência social e inclusão produtiva: algumas indagaçóes. O social em questão. Rio de Janeiro, n.
30, Ano XVII, p. 287-298, 213. Disponível em: <http:// osocialemquestao.ser.puc-rio.br/media/OSQ_30_Souza_14.pdf>. Acesso em 20 mai. 2015.

TODOS SOMOS PORTO ALEGRE. Disponivel em: $<$ http://www.maosverdes.com.br/\#!projetos/c1z1f>. Acesso em 21 jun. 2015.

TRUJILLO, C.M. La política social em Mexico y em Brasil in La integración de políticas públicas para el desarrollo. Brasil e México en perspectiva comparada. Mariana Magaldi de Sousa y Claudia MaldonadoTrujillo (editoras) - México D.F. Centro de Investigacion y Docencia Económicas, 2014.

UNIÃO EUROPEIA. Estratégia Europa 2020 - Plataforma Europeia Contra Pobreza e Exclusão Social. 2011. Disponível em: http://ec.europa.eu/social/BlobServlet?docId=7003\&langId=pt. Acesso em 16 jun. 2015.

ZANELLA, L. Metodologia de estudo e pesquisa em administração. Brasília, CAPES, 2009. 